\title{
GPTMS-Montmorillonite-filled biopolymer chitosan membrane with improved compatibility, physicochemical, and thermal stability properties
}

\author{
Lukman Atmaja a, Mochammad Purwanto ${ }^{\mathrm{b}, \mathrm{c}^{*}}$, Muhammad Taufiq Salleh ${ }^{\mathrm{b}}$, Mohamad Azuwa \\ Mohamed ${ }^{b}$, Juhana Jaafar ${ }^{b,}$, , Ahmad Fauzi Ismail ${ }^{b}$, Mardi Santoso a, Nurul Widiastuti a \\ a Department of Chemistry, Institut Teknologi Sepuluh Nopember, ITS Sukolilo, Surabaya 60111, Indonesia \\ b Advanced Membrane Technology (AMTEC) Research Centre, Universiti Teknologi Malaysia, 81310 UTM Johor Bahru, Malaysia \\ c Institut Teknologi Kalimantan, ITK Karang Joang, Balikpapan 76127, Indonesia \\ *Corresponding authors: juhana@petroleum.utm.my and m.purwanto@itk.ac.id
}

\section{Article history}

Received 5 May 2018

Revised 1 June 2018

Accepted 2 July 2018

Published Online 25 August 2019

\begin{abstract}
The chitosan/organo-montmorillonite (Ch/O-MMT) membrane was fabricated and tested. Surface modification of O-MMT particles using 3-glicydoxy propyl trimethoxysilane (GPTMS) to enhance its compatibility with chitosan is presented. The resulting composite membrane was characterized by using SEM, AFM, and FTIR to observe the morphological and functional group structure. The crystallinity, thermal stability, and mechanical strength was analyzed by XRD, TGA, and tensile test. The results suggested that the modification of MMT using GPTMS could increase the compatibility of O-MMT with chitosan membrane, thus producing a good composite membrane with well-dispersed MMT filler within the chitosan polymer matrices. Based on the FTIR analysis, the presence of GPTMS could improve the interaction between chitosan and O-MMT material, thus forming more hydrogen bonding with chitosan membrane than Ch/MMT membrane. The TGA curve analysis showed that the addition of inorganic filler into chitosan organic matrices was able to increase the thermal stability of $\mathrm{Ch} / \mathrm{MMT}$ and $\mathrm{Ch} / \mathrm{O}-\mathrm{MMT}$ composite membrane, suggested to mechanical strength analysis. The improvement in thermal stability was due to the absence of hydrogen bonding formations between chitosan polymer and O-MMT filler. In addition, greater hydrogen bonding formation would lead to the tighter packing of $\mathrm{Ch} / \mathrm{O}-\mathrm{MMT}$ composite membrane, resulting in higher bonding strength and higher thermal resistance. All of the characterization results confirmed that the Ch/O-MMT composite membrane has better physicochemical properties than $\mathrm{Ch} / \mathrm{MMT}$ composite membrane.
\end{abstract}

Keywords: Chitosan; montmorillonite; (3-glycidoxypropyl) trimethoxysilane; physicochemical properties

(c) 2019 Penerbit UTM Press. All rights reserved

\section{INTRODUCTION}

Chitosan is the second most abundant polysaccharide in the world after cellulose. Although chitosan is not directly available in nature, it can be easily generated through the process of deacetylation of chitin by a strong alkali or prepared from fungal cell walls via fermentation technology. In addition, it can be produced by utilizing marine waste such as shrimp, crab, lobster, and fish shells (Younes et al., 2012). In the recent years, the comprehensive utilization of chitosan as bio-based polymer has drawn elevated attention for various functional hybrid materials with tremendous properties for various applications such as medicine, pharmaceutical, food industries, waste water treatment, and energy (Bhattacharyya and Ray 2014; Lewandowska et al., 2014; Y. Liu, et al., 2013; Olad and Farshi Azhar 2014; El Ichi et al. 2015). This wide-ranged application of chitosan is owing to its good mechanical strength, biodegradable, and nontoxic properties (Krishna Rao et al. 2012; Croisier and Jérôme 2013).

It has been reported that the reinforcement of nanomaterial in biopolymeric matrices has greatly improved the physicochemical, mechanical, and thermal stability characteristic of resultants bio- polymer nanocomposites (Sabaa et al., 2015; Petersson, et al., 2007; Mohamed et al., 2016). Recently, the incorporation of layered silicates and montmorillonite (MMT) in chitosan has been extensively studied (Grigoriadi et al. , 2015; Huang et al., 2015; Hong et al., 2011). The use of MMT as a filler in biopolymer is interesting due to its environmental and economic importance. MMT has several advantages including easy to obtain, has a large specific surface area, chemical resistance, strong adsorption capability, good cation exchange capacity and adhesive capability (Ludueña, et al., 2015; Liu, et al., 2008; Zhu et al., 2015; Liu et al., 2011). Wang and co-workers have prepared biopolymer/montmorillonite (CTS/MMT) nanocomposites for adsorption of Congo Red (CR). Compared with pure chitosan, the CTS/MMT nanocomposite has well flocculation ability in aqueous solution, comparative low cost, and relative high adsorption capacity. Therefore, the nanocomposite can be effectively used as an adsorbent for the removal of Congo Red from waste waters.

MMT is a type of clay which consists of layers of tetrahedral silica and octahedral alumina. This material has parallel layers' structure in interrelated form by electrostatic force between layers. The presence of holes in its lattice structure and hydroxyl groups on its surface gives 
MMT good adsorption characteristics and good compatibility with organic compounds (Purwanto et al., 2016). MMT as an inorganic material cannot collaborate perfectly with organic polymer, because the surface layer of montmorillonite cannot interact maximally with the organic portion of the polymer. Organophilization process is one of the promising methods to improve the interaction of MMT in polymer matrices (Jiratumnukul et al., 2012). Huang and co-workers prepared carboxymethyl chitosan/organo-MMT with enhanced thermal stability and antimicrobial activity with complexation with copper ion (Huang et al., 2015). They prepared organo-MMTs by using three novel Gemini cationic surfactants (Gemini 12-2-12, 12-3-12, and 18-3-18) under microwave irradiation (Liu et al. 2011). In addition, Hong Wu et. al., 2007 successfully improved the interaction of zeolite in chitosan matrices by introducing the 3-Aminopropyl-triethoxysilane (APTES) on the surface of the zeolite filler. Wang et al. developed an organicinorganic composite using chitosan as the polymer matrix and zeolite as inorganic filler. Their study indicated that by using (3glycidoxypropyl) trimethoxysilane (GPTMS) to modify the zeolite surface, the new developed composite membrane could achieve denser and stronger surface morphology. On top of that, the immobilization of modified MMT using GPTMS within chitosan matrix would possess superior physicochemical characteristics due to more hydrogen bonding formation introduced by GPTMS. However, to the best of our knowledge, there is yet any research attempt on immobilized modified MMT using GPTMS in chitosan biopolymer matrices. Therefore, it is crucial to study the feasibility of GPTMS-MMT (O-MMT) as filler in chitosan biopolymer matrices with enhanced dispersibility and physicochemical characteristics.

In this study, we prepared chitosan/O-MMT nanocomposite membrane by utilizing dried shrimp shell powder as chitosan source and acetic acid as solvent. The organophilization process of MMT using (3-glycidoxypropyl) trimethoxysilane (GPTMS) would provide excellent compatibility with chitosan membrane. The morphological structure was analyzed by SEM and AFM. The functional groups identification was performed by FTIR. The crystallinity, thermal stability, and mechanical properties analyses was conducted by XRD, TGA and tensile test, respectively.

\section{EXPERIMENTAL}

\section{Materials}

Shrimp shell (Penaeus monodon) was gathered from local fish market. Montmorillonite powder (MMT K-10) and (3glycidoxypropyl) trimethoxysilane (GPTMS) were purchased from Sigma Aldrich. Sodium hydroxide $(\mathrm{NaOH})$, hydrochloric acid $(\mathrm{HCl})$, methanol, acetic acid, toluene, and ethanol in pure analytical grade were purchased from Merck.

\section{Preparation of organo-montmorillonite (O-MMT)}

Modification process of MMT particles to produce organo-MMT (O-MMT) was described in details in our previous study (Purwanto et al. 2016). Briefly, the MMT powder, GPTMS, and toluene were mixed in a reactor. The reaction was carried out at refluxing temperature of toluene $\left(110^{\circ} \mathrm{C}\right)$ under constant stirring condition for 24 hours. Then, the mixture was filtered to retrieve the O-MMT particles. The O-MMT particles were washed with ethanol three times before soaked in a 0.1 $\mathrm{M} \mathrm{HCl}$ solution for 24 hours at room temperature. After that, the particles were washed with distilled water until $\mathrm{pH}$ 6-7 was achieved. Finally, the O-MMT particles were dried in an oven at $100{ }^{\circ} \mathrm{C}$ for 4 hours. Figure 1 shows the design of MMT modification process with reflux system.

\section{Chitosan extraction procedure}

The extraction process of chitosan from shrimp shell was conducted according to the previous study (Trisnawati et al., 2013). The shrimp shell was dried and crushed into fine powder prior to the extraction process. The powder was added into $3.5 \mathrm{wt} \% \mathrm{NaOH}$ solution and stirred for 2 hours at $65{ }^{\circ} \mathrm{C}$. Then, the mixture was filtered to retrieve the precipitate. The precipitate was washed with distilled water until $\mathrm{pH}$ 6-7 then dried. The dry powder was added into $1 \mathrm{M} \mathrm{HCl}$ solution and stirred for 30 minutes at $65{ }^{\circ} \mathrm{C}$. After that, the filtered precipitate was washed and dried. Finally, the precipitate was mixed into 50 wt. $\%$ $\mathrm{NaOH}$ solution and stirred for 4 hours at $120{ }^{\circ} \mathrm{C}$, filtered, washed, and dried to produce chitosan powder.

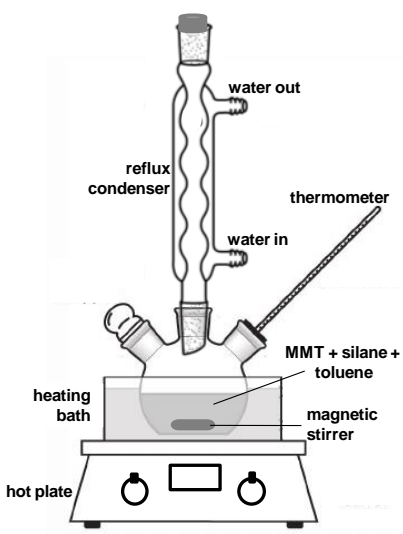

Figure 1 Modification process of MMT particles to produce O-MMT particles.

\section{Pristine chitosan membrane fabrication}

The chitosan powder was added into $2 \mathrm{wt} . \%$ acetic acid and stirred at $80{ }^{\circ} \mathrm{C}$ for 24 hours before undergo sonication process for 30 minutes to produced homogenous solution and remove trapped bubbles. After that, the mixture was cast on a clean glass plate using casting knife and dried at room temperature for 48 hours. The membrane was peeled from the glass plate and immersed in $1 \mathrm{M} \mathrm{NaOH}$ solution for 15 minutes. Finally, the resulted pristine chitosan $(\mathrm{Ch})$ membrane was washed with distilled water several times until $\mathrm{pH}$ 6-7 and dried at room temperature.

\section{Chitosan/MMT and Chitosan/O-MMT composite membranes fabrication}

The chitosan powder and MMT particles were added into two different beakers containing 2 wt.\% acetic acid. The solutions were stirred at $80{ }^{\circ} \mathrm{C}$ for 24 hours and followed by sonication for 30 minutes to produced homogenous solution. Both solutions were mixed together and stirred for 30 minutes at $80{ }^{\circ} \mathrm{C}$ before undergoing degasification process via sonication for 30 minutes. After that, the mixture was cast on a clean glass plate using casting knife and dried at room temperature for 48 hours. The membrane was peeled from the glass plate and immersed in $1 \mathrm{M} \mathrm{NaOH}$ solution for 15 minutes. Finally, the resulted chitosan/MMT (Ch/MMT) composite membrane was washed with distilled water several times until $\mathrm{pH}$ 6-7 and dried at room temperature. Similar procedure was used to fabricate chitosan/O-MMT $(\mathrm{Ch} / \mathrm{O}-$ MMT) membrane.

\section{Membrane characterization}

Fourier Transform Infrared Spectroscopy (FTIR) was conducted using Nicolet Magna 560 IR Spectrometer. 0.1-0.2 g sample and 0.5$1.0 \mathrm{~g}$ of fine grade $\mathrm{KBr}$ was mixed and crushed into powder and pressed using a hydraulic press to form a pallet. The specimen was examined in the transmittance mode with wave number range of 4000 to $650 \mathrm{~cm}^{-1}$.

The morphology of $\mathrm{Ch}$, Ch/MMT, and Ch/O-MMT membranes were analyzed using scanning electron microscopy (SEM) Bruker Analysis. The sample powder was prepared in a pin stub holder and coated with thin layer of gold before the analysis.

Surface roughness of $\mathrm{Ch}, \mathrm{Ch} / \mathrm{MMT}$, and $\mathrm{Ch} / \mathrm{O}-\mathrm{MMT}$ membranes were studied using Atomic Force Microscopy (AFM) XE-100 Park System.

The crystallinity study was carried out using Philips Analytical XRD diffractometer with $\mathrm{Cu}-\mathrm{K} \alpha$ radiation $(\lambda=0.154056 \AA)$. The diffractogram was scanned in the ranges from $5-50^{\circ}$.

Thermogravimetric analysis (TGA) was carried out using a Mettler Toledo $851 \mathrm{e}$ TGA thermogravimetric analyzer. The specimen was heated from room temperature to $800{ }^{\circ} \mathrm{C}$ at $10{ }^{\circ} \mathrm{C} \mathrm{min}-1$ rate under 30 $\mathrm{mL} \min ^{-1}$ air flow.

Tensile tests were performed using Toyoseiki VG10E, according to ASTM D882 device at room temperature at a constant cross-head speed of $10 \mathrm{~mm} \mathrm{~min}^{-1}$ and $100 \mathrm{~N}$ load cell. The samples was dumbbell-shaped 
with gauge dimensions of $15 \mathrm{~mm} \times 3 \mathrm{~mm} \times 0.22 \mathrm{~mm}$. Force $(\mathrm{N})$ and deformation $(\mathrm{mm})$ where recorded during the test.

\section{RESULTS AND DISCUSSION}

\section{Morphological analysis of pure chitosan membrane, $\mathrm{Ch} / \mathrm{MMT}$ and Ch/O-MMT composite membrane}

The SEM images for $\mathrm{Ch}, \mathrm{Ch} / \mathrm{MMT}$, and $\mathrm{Ch} / \mathrm{O}-\mathrm{MMT}$ membranes are presented in Figure 2. Based on Figure 2 (a), the Ch membrane shows smooth dense structure. On the other hand, after incorporating the MMT particles in chitosan matrix, the $\mathrm{Ch} / \mathrm{MMT}$ composite membrane showed visible particles agglomeration (yellow circle) and pin hole (red circles) on its surface (Figure 2b). This phenomenon occurred due to incompatibility between inorganic filler and organic matrix. The incompatibility between chitosan organic polymer and MMT inorganic particles caused phase separation in Ch/MMT composite membrane. Therefore, the MMT particles have the tendency to accumulate and agglomerate inside the $\mathrm{Ch} / \mathrm{MMT}$ composite membrane's matrix. The similar results have been reported in previous study (Wang et al. 2010b).
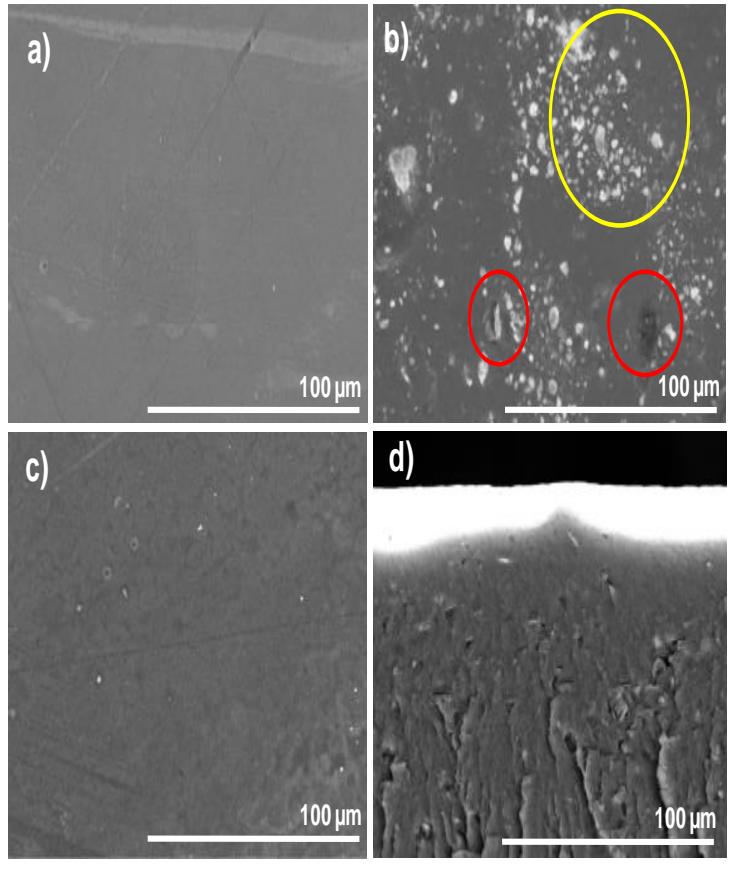

Figure 2 SEM images of Ch (a), Ch/MMT (b), andCh/O-MMT (c) membranes' surface. Image (d) showed the cross sectional of $\mathrm{Ch} / \mathrm{O}$ MMT membranes.

Based on Figure 2(c), the morphology of Ch/O-MMT composite membrane improved and became more homogenous compared to the $\mathrm{Ch} / \mathrm{MMT}$ composite membrane. No agglomeration and pin hole can be seen on the surface of the $\mathrm{Ch} / \mathrm{O}-\mathrm{MMT}$ composite membrane as shown in Figure 2(c). The cross-section image of the Ch/O-MMT composite membrane shows that the O-MMT particles is well dispersed in the chitosan matrix (Figure 2(d)). The SEM images proved that the MMT modification with GPTMS organic compound could improve the compatibility and interaction between the chitosan organic polymer and MMT inorganic particles. The enhanced dispersibility due to the presence of hydroxyl group of O-MMT has improved the phase interaction between chitosan and O-MMT. The good interaction occurred between hydroxyl groups of O-MMT and hydroxyl groups or amide groups of the chitosan polymer chain. (Purwanto et al. 2016).

Figure 3 shows $2 \mathrm{D}$ and $3 \mathrm{D}$ AFM images of $\mathrm{Ch}, \mathrm{Ch} / \mathrm{MMT}$, and $\mathrm{Ch} / \mathrm{O}-\mathrm{MMT}$ membranes. It was found that incorporation of the MMT particles increased surface roughness of the $\mathrm{Ch} / \mathrm{MMT}$ composite membrane (Figure 3 (b)) compared to the Ch membrane, due to the incompatibility between montmorillonite as inorganic filler and chitosan organic material (Figure 3 (a)). On the contrary, the AFM image of the Ch/O-MMT composite membrane (Figure 3 (c)) shows smoother surface as compared to the $\mathrm{Ch}$ and $\mathrm{Ch} / \mathrm{MMT}$ membranes. This result showed that the O-MMT particles can improve the $\mathrm{Ch} / \mathrm{O}$ MMT surface roughness.
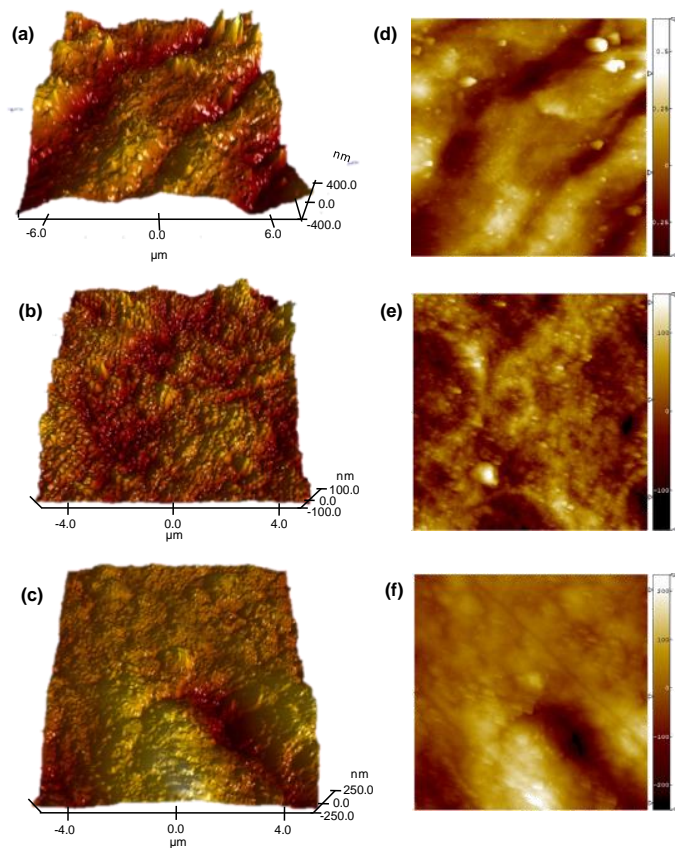

Figure 3 3D and 2D AFM images morphology of Ch (a, d), Ch/MMT (b, e), and Ch/O-MMT composite membrane (c, f).

\section{FT-IR analysis}

Figure 4 shows the FT-IR results of $\mathrm{Ch}, \mathrm{Ch} / \mathrm{MMT}$, and $\mathrm{Ch} / \mathrm{O}-\mathrm{MMT}$ membranes. Three peaks at $3350 \mathrm{~cm}^{-1}, 1650 \mathrm{~cm}^{-1}$, and $1560 \mathrm{~cm}^{-1}$ were corresponding to hydroxyl, amide I, and amide II groups, respectively (Wang et al. 2008). Three peaks at $2930 \mathrm{~cm}^{-1}, 1390 \mathrm{~cm}^{-1}$ and $1030 \mathrm{~cm}^{-1}$ were assigned to $-\mathrm{CH}_{2}$ stretching, $-\mathrm{CH}_{2}$ bending, and $\mathrm{C}-\mathrm{O}$ stretching, respectively(Wang et al. 2010b). These groups are the main functional groups for chitosan polymer. The FT-IR spectra of the $\mathrm{Ch} / \mathrm{MMT}$ and Ch/O-MMT composite membranes were identical with the $\mathrm{Ch}$ membrane with two distinctive differences. First, the two bands at 1030 $\mathrm{cm}^{-1}$ and $1010 \mathrm{~cm}^{-1}$ were merged and shifted towards $1030 \mathrm{~cm}^{-1}$. This occurrence happened due to the overlapping of $\mathrm{Si}-\mathrm{O}$ band with the $\mathrm{C}-$ O stretching band (Olad and Farshi Azhar 2014; Wu et al. 2007). Second, the intensity of the hydroxyl group, amide I, and amide II bands for the $\mathrm{Ch} / \mathrm{MMT}$ and $\mathrm{Ch} / \mathrm{O}-\mathrm{MMT}$ composite membranes were significantly lower. This phenomenon might be due to formation of hydrogen bonding between the - $\mathrm{OH}$ groups on the MMT and O-MMT particles with $-\mathrm{OH}$ and $-\mathrm{NH}_{2}$ groups on the chitosan polymer.

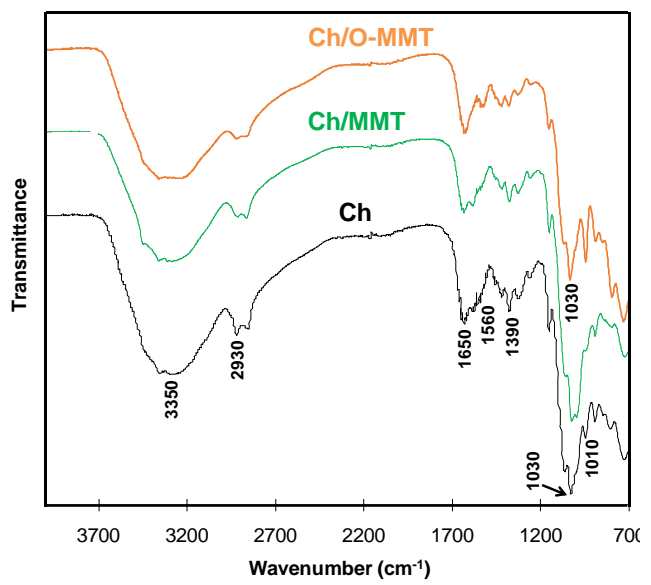

Figure 4 FTIR spectra of $\mathrm{Ch}, \mathrm{Ch} / \mathrm{MMT}$, and Ch/O-MMT.

The hydrogen bonding formations between chitosan polymer and MMT and O-MMT particles are illustrated in Figure 4 (b) and (c) 
respectively. Based on the Figure 4 (c), the presence of GPTMS modifier on the O-MMT surface could increase the $-\mathrm{OH}$ group. Therefore, higher hydrogen bonding can be formed between O-MMT particles and the chitosan polymer. Hence, the intensity of hydroxyl group, amide I, and amide II for the $\mathrm{Ch} / \mathrm{O}-\mathrm{MMT}$ composite membrane was lower as compared to that of the $\mathrm{Ch} / \mathrm{MMT}$ composite membrane. This result proved that incorporation of the GPTMS modifier on the OMMT particle could increase the O-MMT particles compatibility with the chitosan polymer.

\section{XRD Analysis}

Figure 5 shows the XRD spectra of MMT, O-MMT, Ch/MMT, and $\mathrm{Ch} / \mathrm{O}-\mathrm{MMT}$. Based on the figure, two intense peaks were observed at $20.9^{\circ}$ and $26.8^{\circ}$ for both the MMT and O-MMT particles. This observation indicated that the O-MMT surface modification by GPTMS did not change the crystalline structure of the MMT and only modified the MMT surface properties. Interestingly, the corresponding peak did not change its position but reduced in intensity for O-MMT sample. Similar observation also has been reported in previous study (Wang et al. 2010a).

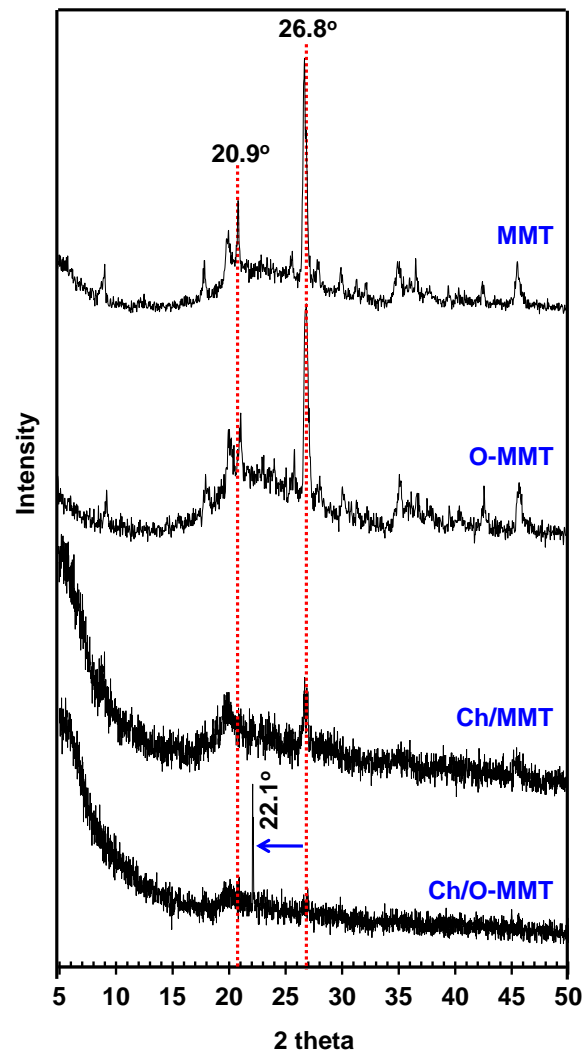

Figure 5 XRD patterns of MMT and O-MMT particles, Ch/MMT and Ch/O-MMT membranes.

In Figure 5, it is apparent that the intensity of the MMT and OMMT are reduced significantly after they have been immobilized in chitosan membrane matrix. The XRD pattern of $\mathrm{Ch} / \mathrm{MMT}$ and $\mathrm{Ch} / \mathrm{O}-$ MMT presented a diffraction peak at $20.9^{\circ}$ and $26.8^{\circ}$, but shifted to low intensity. This is indicative of an intercalated structure where the polymer chains are incorporated between the silicate layers, increasing their gallery height but maintaining their layered stacking with alternating polymer silicate layers (Giannakas et al., 2014). Therefore, chitosan composite membrane with a significant intercalated structure have been prepared as a result of the good compatibility of chitosan with clay especially O-MMT which in good agreement with SEM analysis. In addition, the immobilization of O-MMT within the chitosan matrix lead to a decrease of the diffraction peaks intensities and exhibited a new peak at $22.1^{\circ}$, thus demonstrated that a new intercalation of O-MMT was formed by electrostatic self-assembly. It is assumed that in $\mathrm{Ch} / \mathrm{O}-\mathrm{MMT}$ composite membrane, a disordered, intercalated, or exfoliated structure appeared and increased to weaker electrostatic, ion exchange, and hydrogen bond interactions between chitosan, MMT, water, and GPTMS (Zhu et al., 2015).

\section{Thermal stability analysis}

The TGA analysis was carried out to evaluate the thermal stability of the $\mathrm{Ch}, \mathrm{Ch} / \mathrm{MMT}$, and $\mathrm{Ch} / \mathrm{O}-\mathrm{MMT}$ membranes. As shown in Figure 6 , all membranes show three stages of weight loss. The first stage that happened below $175^{\circ} \mathrm{C}$ which was attributed to the evaporation of absorbed water (Santos et al., 2015; Lewandowska et al., 2014). The second stage happened at $175-400^{\circ} \mathrm{C}$ interval because of the chitosan polymer chain degradation, and the last stage happened after $400^{\circ} \mathrm{C}$ due to the decomposition of residual organic group (Y. Wang et al., 2010a). The incorporation of GPTMS has improved the interaction of MMT with chitosan by introducing more functional groups, so increasing of thermal stability of Ch/O-MMT composite membrane. The greater hydrogen bond formation was expected in Ch/O-MMT membrane rather than in $\mathrm{Ch} / \mathrm{MMT}$ membrane. Consequently, the $\mathrm{Ch} / \mathrm{O}-\mathrm{MMT}$ membrane becomes tighter and stronger than $\mathrm{Ch} / \mathrm{MMT}$ membrane, thus giving the $\mathrm{Ch} / \mathrm{O}-\mathrm{MMT}$ membrane higher thermal stability characteristics compared to $\mathrm{Ch} / \mathrm{MMT}$ membrane. These results were in good agreement with previously reported values for chitosan composites (Lewandowska et al., 2014), where montmorillonite without modification, and montmorillonite after surface modification with octadecylamine were more thermally stable than chitosan as indicated by appearance of peak at a higher temperature.

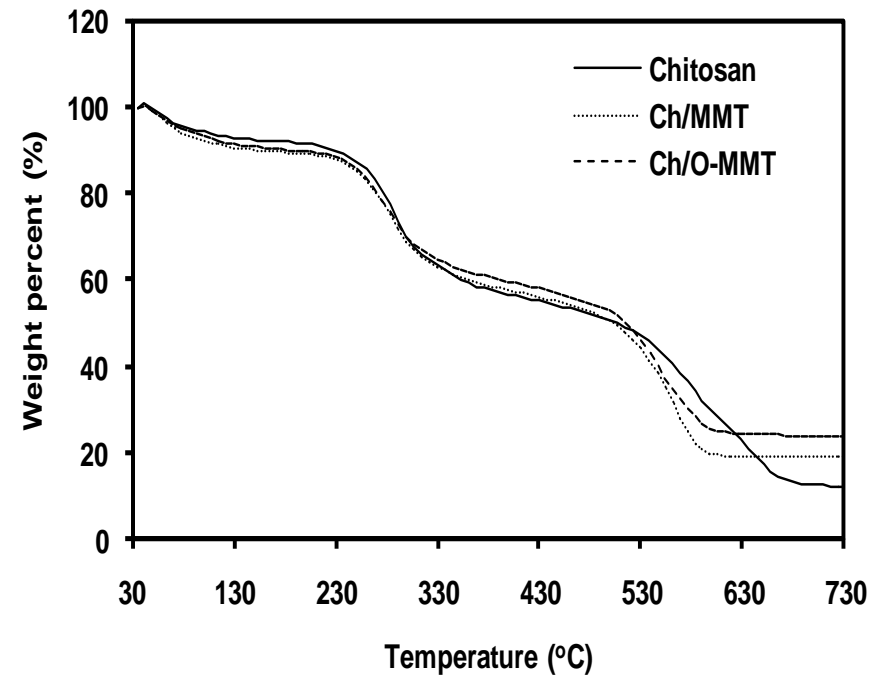

Figure 6 TGA curves for pristine $\mathrm{Ch}, \mathrm{Ch} / \mathrm{MMT}$, and Ch/O-MMT membranes.

\section{Mechanical properties}

The effect of MMT modification by GPTMS on the tensile response of the composite membrane is depicted in Table 1 . The addition of GPTMS resulted in a direct increasing of the stiffness and the strength of the Ch/O-MMT. As seen in Table 2, the elongation at break for $\mathrm{Ch} / \mathrm{O}-\mathrm{MMT}$ increased up to $20.40 \%$ which was higher than that of Ch/MMT $(6.48 \%)$ and neat chitosan $(3.31 \%)$. The Ch/O-MMT composite membrane presented higher mechanical strength compared to Ch/MMT-Gly $(9.58 \%$ ) (Giannakas et al., 2014) and Ch/MMT-PES (13.70\%) (Zhu et al., 2015). The phenomenon can be explained by the high amount of electrostatic interactions between the O-MMT and chitosan. It was assumed that more water and GPTMS were distributed within the chitosan network of a hydrogen bonding mechanism, inducing a very obvious plasticization effect. Similar trends have been reported in the previous study regarding the mechanical properties of Ch/MMT-Gly composites (Giannakas et al., 2014). They have found that the addition of glycerol as crossing agent resulted in an increase in the elongation at break, which was associated with the more homogenous distribution of water and glycerol across the system, resulting in better plasticization effect (Giannakas et al., 2014). 
Table 1 Overall characteristics of the $\mathrm{Ch}$ and Ch composite membranes.

\begin{tabular}{|c|c|c|c|c|}
\hline Membrane & $\begin{array}{l}\text { Solvent } \\
\text { aqueous/ } \\
\text { preparing } \\
\text { system }\end{array}$ & $\begin{array}{l}\text { Structure } \\
\text { properties }\end{array}$ & $\begin{array}{l}\text { Elongatio } \\
\mathrm{n} \text { at } \\
\text { break (\%) }\end{array}$ & Reference \\
\hline $\mathrm{Ch}$ & $\begin{array}{l}2 \% \text { acetic } \\
\text { acid/1 M } \\
\mathrm{NaOH}\end{array}$ & $\begin{array}{l}\text { Homogenous } \\
\text { symmetric } \\
\text { dense } \\
\text { structure }\end{array}$ & 3.31 & $\begin{array}{l}\text { In this } \\
\text { work }\end{array}$ \\
\hline $\mathrm{Ch} / \mathrm{MMT}$ & $\begin{array}{l}2 \% \text { acetic } \\
\text { acid } / 1 \mathrm{M} \\
\mathrm{NaOH}\end{array}$ & $\begin{array}{l}\text { Dense } \\
\text { agglomeration } \\
\text { structure }\end{array}$ & 6.48 & $\begin{array}{l}\text { In this } \\
\text { work }\end{array}$ \\
\hline Ch/O-MMT & $\begin{array}{l}2 \% \text { acetic } \\
\text { acid } / 1 \mathrm{M} \\
\mathrm{NaOH}\end{array}$ & $\begin{array}{l}\text { Dense } \\
\text { dispersion } \\
\text { structure }\end{array}$ & 20.40 & $\begin{array}{l}\text { In this } \\
\text { work }\end{array}$ \\
\hline $\begin{array}{l}\text { Ch/MMT- } \\
\text { Gly }\end{array}$ & $\begin{array}{l}0.5 \% \\
\text { acetic acid } \\
(\mathrm{HAc})\end{array}$ & $\begin{array}{l}\text { Dense } \\
\text { compatibility } \\
\text { structure }\end{array}$ & 9.58 & $\begin{array}{l}\text { (Giannaka } \\
\text { s et al., } \\
2014 \text { ) }\end{array}$ \\
\hline $\begin{array}{l}\text { Ch/MMT- } \\
\text { PES }\end{array}$ & $\begin{array}{l}2 \% \text { acetic } \\
\text { acid/ } \\
\text { DMAc }\end{array}$ & $\begin{array}{l}\text { Finger-like } \\
\text { porous } \\
\text { structure }\end{array}$ & 13.70 & $\begin{array}{l}\text { (Zhu et al., } \\
\text { 2015) }\end{array}$ \\
\hline
\end{tabular}

\section{CONCLUSION}

$\mathrm{Ch} / \mathrm{MMT}$ and $\mathrm{Ch} / \mathrm{O}-\mathrm{MMT}$ composite membranes were successfully prepared. The morphological analysis, SEM, and AFM images showed that the O-MMT filler has better dispersion and smoother surface structure than MMT filler in chitosan polymer matrices. FT-IR spectra showed that the intensity hydroxyl, amide I, and amide II from chitosan membrane decreased with the addition of MMT and O-MMT filler, which happens due to formation bonding between chitosan polymer and MMT/O-MMT filler. The incorporation of GPTMS on O-MMT surface was able to increase the compatibility of O-MMT with chitosan membrane, as seen from the FT-IR results. The TGA curve analysis demonstrated that the addition of inorganic filler into chitosan organic matrices was able to increase the thermal stability of $\mathrm{Ch} / \mathrm{MMT}$ and $\mathrm{Ch} / \mathrm{O}-\mathrm{MMT}$ composite membrane, suggested to mechanical strength analysis. The improvement in thermal stability is due to the facts that there are more hydrogen bonding formations between chitosan polymer and O-MMT filler, compared to that of between chitosan polymer and O-MMT filler. In addition, greater hydrogen bonding formation would lead to the tighter packing of $\mathrm{Ch} / \mathrm{O}$ MMT composite membrane, resulting in higher bonding strength and higher thermal resistance. All of the characterization results confirmed that the $\mathrm{Ch} / \mathrm{O}-\mathrm{MMT}$ composite membrane has better physicochemical properties than $\mathrm{Ch} / \mathrm{MMT}$ composite membrane.

\section{ACKNOWLEDGEMENT}

The authors would like to express gratitude to Universiti Teknologi Malaysia (UTM) and Ministry of Science, Technology and Innovation (MOSTI), Malaysia for the financial support grants with vote number of R.J130000.7809.4F592, Q.J130000.2509.05H52 and R.J130000.7942.4S507 and to the Institut Teknologi Sepuluh Nopember (ITS) and Ministry of Research, Technology and Higher Education, Indonesia with contract number of 0167/IT2.11/PN.08.

\section{REFERENCES}

Bhattacharyya, Ruma, Samit, K. R. 2014. Micro- and nano-sized bentonite filled composite superabsorbents of chitosan and acrylic copolymer for removal of synthetic dyes from water. Applied Clay Science, 101(November): 510 20.

Chatterjee, S., M. Adhya, A. K. Guha, B.P. Chatterjee. 2005. Chitosan from mucor rouxii: Production and physico-chemical characterization. Process Biochemistry, 40(1): 395-400.

Croisier, Florence, Jérôme, C. 2013. Chitosan-based biomaterials for tissue Engineering. European Polymer Journal, 49(4): 780-92.

Giannakas, Aris, Grigoriadi, K., Leontiou, A., Barkoula, Ladavos, A. 2014 preparation, characterization, mechanical and barrier properties investigation of chitosan-clay nanocomposites. Carbohydrate Polymers,
108(1): 103-111.

Grigoriadi, Kalouda, Giannakas, A., Ladavos, A. K., Barkoula. N. M. 2015. Interplay between Processing and performance in chitosan-based clay nanocomposite films. Polymer Bulletin, 72(5): 1145-1161.

Hong, I., Seung, Lee, J. H., Bae, H. J., Koo, S. Y., Lee, H. S., Choi, J. H., Dong Kim, D. H., Park, S-H., Park, H. J. 2011. Effect of shear rate on structural, mechanical, and barrier properties of chitosan/montmorillonite nanocomposite film. Journal of Applied Polymer Science, 119(5): 2742 2749.

Huang, Yongcan, Huang, J., Cai, J., Lin, W., Lin, Q., Wu, F., Luo, J. 2015. Carboxymethyl chitosan/clay nanocomposites and their copper complexes: fabrication and property. Carbohydrate Polymers, 134: 390-397.

Huskić, M., Brnardić, I., Žigon, M., Ivanković, M. 2008. Modification of montmorillonite by quaternary polyesters. Journal of Non-Crystalline Solids, 354(28): 3326-3331.

Ichi, El, S., Zebda, A., Alcaraz, J.-P., Laaroussi, A., Boucher, F., Boutonnat, J., Reverdy-Bruas, N., et al. 2015. Bioelectrodes modified with chitosan for long-term energy supply from the body. Energy \& Environmental Science, (3): $1017-1026$

Jiratumnukul, Nantana, Manowanna, P., Premmag, N. 2012. Modified Bentonite clay in UV-Curable coating applications. Engineering Journal, 16(3): 1318.

Krishna Rao, K.S.V., Ramasubba Reddy, P., Yong-III L., Kim, C. 2012. Synthesis and characterization of chitosan-PEG-Ag nanocomposites for antimicrobial application. Carbohydrate Polymers, 87(1): 920-925.

Lewandowska, Katarzyna, Sionkowska, A., Kaczmarek, B., Furtos, G. 2014. Characterization of chitosan composites with various clays. International Journal of Biological Macromolecules, 65: 534-541.

Liu, Bo, Wang, X., Yang, B., Sun, R. 2011. Rapid Modification of montmorillonite with novel cationic gemini surfactants and its adsorption for methyl orange. Materials Chemistry and Physics, 130(3): 1220-1226.

Liu, Xiao-Wen, Hu, M., Yue-hua, H. 2008. Chemical composition and surface charge properties of montmorillonite. Journal of Central South University of Technology, 15(2): 193-197.

Liu, Yan, Yang, S., Niu, W. 2013. Simple, rapid and green one-step strategy to synthesis of graphene/carbon nanotubes/chitosan hybrid as solid-phase extraction for square-wave voltammetric detection of methyl parathion. Colloids and Surfaces. B, Biointerfaces, 108: 266-270.

Ludueña, Leandro, Morán, J., Alvarez, V. 2015. Biodegradable Polymer/clay nanocomposites. In Eco-Friendly Polymer Nanocomposites, edited by Vijay Kumar Thakur and Manju Kumari Thakur, 75thed., 109-135. Springer India.

Mohamed, Azuwa, M., Salleh, W.N. W., Jaafar, J., Ismail, A. F., Mutalib, M. A.,. Sani, N. A. A., Asri, S. E. A. M., Ong, C. S. 2016. Physicochemical characteristic of regenerated cellulose/n-doped tio2 nanocomposite membrane fabricated from recycled newspaper with photocatalytic activity under UV and visible light irradiation. Chemical Engineering Journal, 284: 202-215.

Oguzlu, Hale, Tihminlioglu, F. 2010. Preparation and barrier properties of chitosan-layered silicate nanocomposite films. Macromolecular Symposia, 298(1): 91-98.

Olad, Ali, Azhar, F. F. 2014. The synergetic effect of bioactive ceramic and nanoclay on the properties of chitosan-gelatin/nanohydroxyapatitemontmorillonite scaffold for bone tissue engineering. Ceramics International, 40(7): 10061-10072.

Petersson, L., I. Kvien, and K. Oksman. 2007. Structure and thermal properties of poly (lactic acid)/cellulose whiskers nanocomposite materials. Composites Science and Technology, 67(11-12): 2535-2544.

Purwanto, Mochammad, Atmaja, L., Mohamed, M. A., Salleh, M. T., Jaafar, J., Ismail, A. F., Santoso, M., Widiastuti, N. 2016. Biopolymer-based electrolyte membranes from chitosan incorporated with montmorillonitecrosslinked gptms for direct methanol fuel cells. RSC Advances, 6(3): 2314 2322.

Sabaa, Magdy, W., Heba, M. A., Mohamed, N. A., Mohamed, R. R. 2015. Synthesis, Characterization and application of biodegradable crosslinked carboxymethyl chitosan/poly (vinyl Alcohol) clay nanocomposites. Materials Science \& Engineering C, Materials for Biological Applications, 56: 363-373.

Sagheer, Al, M. A., Al-Sughayer, Muslim, S., Elsabee, M. Z. 2009. Extraction and characterization of chitin and chitosan from marine sources in arabian gulf. Carbohydrate Polymers, 77(2): 410-419.

Santos, Dos, B. R., Bacalhau, F. B., Pereira, T. D. S., Souza, C. F., Faez, R. 2015. Chitosan-montmorillonite microspheres: A sustainable fertilizer delivery system. Carbohydrate Polymers, 127: 340-346.

Trisnawati, Elin, Andesti, D., Saleh, A. 2013. Pembuatan kitosan dari limbah cangkang kepiting sebagai bahan pengawet buah duku dengan variasi lama pengawetan. Jurnal Teknik Kimia, 19(2): 17-26.

Wang, Li, Wang, A. 2007. Adsorption characteristics of congo red onto the chitosan/montmorillonite nanocomposite. Journal of Hazardous Materials, 147(3): 979-985. 
Wang, Yabo, Jiang, Z., Li, H., Yang, D. 2010a. Chitosan membranes filled by GPTMS-modified zeolite beta particles with low methanol permeability for DMFC. Chemical Engineering and Processing: Process Intensification, 49 (3): $278-285$.

Wang, Yabo, Yang, D., Zheng, X., Jiang, Z., Li, J. 2008. Zeolite Beta-filled chitosan membrane with low methanol permeability for direct methanol fuel cell. Journal of Power Sources, 183(2): 454-463.

Wu, Hong, Zheng, B., Zheng, X., Wang, J., Yuan, W., Jiang, Z. 2007. Surfacemodified Y zeolite-filled chitosan membrane for direct methanol fuel cell. Journal of Power Sources, 173(2): 842-852.

Younes, Islem, Ghorbel-Bellaaj, O., Nasri, R., Chaabouni, M., Rinaudo,M., Nasri, M. 2012. Chitin and Chitosan preparation from shrimp shells using optimized enzymatic deproteinization. Process Biochemistry, 47 (12): 2032-2039.

Zhu, Junyong, Tian, M., Zhang, Y., Zhang, H., Liu, J. 2015. Fabrication of a novel 'loose' nanofiltration membrane by facile blending with chitosanmontmorillonite nanosheets for dyes purification. Chemical Engineering, Journal 265: 184-193. 